\title{
АУРИКУЛОТЕРАПИЯ В КОМПЛЕКСНОМ ЛЕЧЕНИИ ХРОНИЧЕСКОЙ ЕЖЕДНЕВНОЙ ГОЛОВНОЙ БОЛИ
}

\author{
*Тахмазов P.P. \\ Аз ГИУВ им. А.Алиева, кафедра нервных болезней, Баку
}

В представленной работе впервые показаны достоверные преимущества комплнесного применения ауриколотерапии совместно с медикаментозным лечением по сравнению с применением медикаментозной и аурикулотерапии по отдельности. Более того в данной работе продемонстрированы преимущества дифференцированного выбора аурикулярных зон перед выбором аурикулярных зон, где используются биологически активные точки «общего действия», а также перед медикаментозным лечением.

Ключевые слова: аурикулотерапия, немедикаментозная терапия, акупунктура.

B наше время, время научнотехнического прогресса, высоких скоростей и роста социальных проблем, хроническая ежедневная головная боль (ХЕГБ) по данным ряда авторов [1], является одной из наиболее распространенных патологий.

Наиболее перспективным в этой ситуации является разработка новых, более эффективных методов терапии, среди которых особое место отводится методам Восточной (традиционной) медицины [2].

Сведения об использовании в лечении ХЕГБ методов Восточной медицины, приносят обнадеживающие результаты, приводящие к возможности снижения доз применяемых ненаркотических анальгетиков и антидепрессантов и тем самым в снижении вероятности возникновения аллергических реакций [3].

Немедикаментозная терапия позволяет снизить экономические потери связанные с заболеванием [4] и социальные затраты на реабилитацию [5].

Несмотря на то, что в последние годы в нашей республике и за рубежом при лечении ХЕГБ нашли применение различные методы Восточной медицины, многие вопросы остаются нерешенными, так как не имеется единой методики, нередко описываются противоречивые методические приемы, что затрудняет более широкое внедрение их в практику здравоохранения.

Одним из методов Восточной медицины является акупунктура, лечебные эффекты которой очевидны при хронических болевых синдромах. Как показали многочисленные клинические и экспериментальные исследования [6], акупунктура снижает активность ноцицептивной системы и стимулирует антиноноцицептивную систему.

В этой связи представляет интерес применение акупунктуры в лечении ХЕГБ. В научной медицинской литературе по этой проблеме имеются единичные наблюдения [7].

Кроме того, лечебное применение такой акупунктурной микросистемы как область ушной раковины (аурикулотерапия - АТ) позволяет оказывать дифференцированное влияние практически на все системы организма. Однако исследований по комплексному применению аурикулотерапии и медикаментозного лечения в доступной литературе не обнаружено.

Таким образом, перечисленные выше вопросы, а именно, значительная распространенность ХЕГБ, многочисленные побочные эффекты в случае применения медикаментозной терапии, отсутствие данных о возможной роли аурикулотерапии в лечении ХЕГБ являются весьма важными для практического здравоохранения и попытка их разрешения является очень актуальной в *rishad.baku@gmail.com 
целом.

Учитывая вышесказанное, было проведено исследование, целью которого было определение эффективности использования аурикулодиагностики и аурикулотерапии у пациентов с ХЕГБ.

Было обследовано 90 пациентов с хронической ежедневной головной болью. Диагностика ХЕГБ проводилась на основании критериев, предложенных Silberstein с соавторами (1994) [8], по которым к ХЕГБ относят головные боли (ГБ) длительностью не менее 4 часов в сутки, не менее 15 дней в месяц, не менее 6 месяцев в году.

Для исключения вторичного характера ГБ всем пациентам проводилась рентгенография шейного отдела позвоночника, электроэнцефалография и при необходимости ультразвуковая доплерография, транскраниальная доплерография и магнитнорезонансная томография головного мозга.

Bce больные, в зависимости от применявшегося метода лечения, были рандомизировано разделены на 3 группы по 30 человек в каждой.

Под наблюдением находились 90 больных с ХЕГБ. Из данных больных сформированы три статистически сопоставимые группы. Больные I группы (30 человек) получали дифференцированную аурикулотерапию в комплексе с медикаментозным лечением; во II группе из 30 человек назначали только аурикулотерапию, используя стандартно применяемые акупунктурные зоны; в III группе (сравнения) из 30 человек назначали только медикаментозную терапию (цитрамон, аналгин, нурофен, седалгин и др.).

Методы исследования.

В работе использованы нижеследующие методы исследования:

- Клинико-неврологическое обследование.

- Шкала общего клинического впечатления (GGI).

Тяжесть состояния больных оценивалась по шкале общего клинического впечатления (GGI, National Institut of Mental Health Maryland 1976) - включавшую баллированную оценку тяжести заболевания до лечения, глобальную оценку тяжести заболевания до лечения, глобальную оценку динамики состояния после лечения и показатель эффективности терапии после лечения.

Визуально-аналоговая шкала.

Клиническая оценка болевого синдрома и эффективности терапии осуществлялась по визуально-аналоговой шкале (ВАШ), путем определения интенсивности ГБ в баллах до и после лечения.

Дневник головной боли.

Исследования больных с головной болью основываются, прежде всего, на субъективных ощущениях, и в Международной классификации головных болей приведены критерии этих ощущений, характерных для определенного вида ГБ. Для уточнения этих особенностей будет применен специальный дневник ГБ, который включает в себя ряд вопросов: 1) локализация; 2) характер боли; 3) течение; 4) длительность болевых приступов и ощущений; 5) время их возникновения; 6) сопровождающие симптомы; 7) поведение пациента в период болевой атаки; 8) факторы, провоцирующие боль и облегчающие боль; 9) какие и в каком количестве препараты принимаетпациент, степень их эффективности и длительность приема; 10) возраст дебюта заболевания; 11) наличие других заболеваний, вредных привычек; 12) наследственный фактор; наличие стрессогенных ситуаций; 13) наличие стрессогенных ситуаций; 14) влияние ГБ на работоспособность в период приступа

Определение индекса головной боли.

Оценка эффективности лечения проводилась по степени изменения головной боли (ИГБ), который расчитывался по формуле: ИГБ= частота ГБ (количество дней с ГБ в месяц) х длительность (количество часов ГБ в день) х интенсивность ГБ (баллы ВАШ) $/ 30$.

Всем больным включенным в исследование проводилась аурикуло- и пульсовая диагностика.

Пульсовая диагностика проводилась с помощью программы компьютерного пульсодиагностичекого комплекса «WinPulse» (РНЦХ РАМН). Концепция данной 
программы основана на положениях теории пяти первоэлементов и учении о меридианах организма человека, принятой в Восточной медицине. Прообразом программы является широко распространненый на Востоке метод диагностики, основанный на изучении изменений характера пульса пальпацией в конкретных точках поверхности тела. Использование датчика пульсовой волны заменяет многолетнию тренировку чувствительности пальцев врачапульсодиагноста. Кроме того, все больным включенным в исследование были применены современные диагностические методы (ЯМР, УЗИ, компьютерной томографии и др.).

Аурикулотерапия проводилась путем воздействия на зоны соматотопии органов на поверхности ушной раковины. Лечение проводилось курсом из 10 процедур, выполняемых через день-два.

Воздействие осуществлялось с помощью микроигл на акупунктурные зоны ушной раковины с разной экспозицией. С целью осуществления седативного влияния микроиглы устанавливались в аурикулярные точки на срок до двух-трех дней, для проведения тонизации - не более трёх минут. Тем самым достигалось дифференцированное (седатирующее или тонизирующее) влияние на точки. Выбор акупунктурных точек и вида воздействия зависел от клинических особенностей течения ХЕГБ.

С целью изучения влияния различных видов лечения ХЕГБ, больные были разделены на три группы: I группа больных получала дифференцированную аурикулотерапию и медикаментозное лечение, II группа только стандартную аурикулотерапию, с воздействием на акупунктурные зоны «общего действия», и III группа - медикаментозное лечение без применения аурикулотерапии. Результаты лечения оценивали как после проведения курса лечения, так и через шесть месяцев после лечения.

У пациентов I группы дифференцированый выбор тех или иных акупунктурных зон ушной раковины проводился в зависимости от локализации головных болей. При этом использовались акупунктуные зоны уха, соответствующие биологически активные точки (БАТ) внутренних органов.

При этом для дифференцированного (симпатического или парасимпатического) влияния на БАТ, расположенных на ушной раковине избраны методы тонизации и седации.

В литературе приводятся стандартные схемы аурикулотерапии для использования при головных болях. Предлагается применение точек ушной раковины, относящихся к так называемым «зонам общего действия» [9]. Например, АР25 - «гипофиза», AР34 - «коры головного мозга», АР51 «симпатическая», АР55 - «ворота бога», АР78 -«противовоспалительная, противоболевая» и др.

Поэтому для сравнительной оценки эффективности именно дифференцированной аурикулотерапии в лечении ХЕГБ была сформирована II группа пациентов, с применением «стандартного» подхода к аурикулотерапии.

При изучении клинических признаков течения синдрома в трёх лечебных группах, после проведенного лечения, было отмечено статистически достоверное $(\mathrm{P}<0,001)$ улучшение самочувствия у всех больных. Это выражалось в уменьшении, а у ряда больных в исчезновении ведущих симптомов головной боли. Тем не менее, несмотря на общую положительную динамику в группах, именно у пациентов I группы наблюдалось более быстроеикачественнолучшеевосстановление самочувствия, чем во II и III группах $(\mathrm{P}<0,05)$. Это позволяет предположить соответствие лечебной тактики, примененной в I группе, действительнымсаногенетическимпроцессам в организме больных.

Независимо от достоверности $(\mathrm{P}<0,05)$ восстановления показателей гуморального и клеточного иммунитета, в ходе иммунного анализа не замечено достоверной разницы между показателями трёх групп (P>0,1). Данные результаты, вероятно, могут быть связаны с особенностями процессов реагирования иммунных структур 
на проводимую терапию в течение трехнедельного периода лечения.

Таким образом, оценка результатов непосредственно после проведенного курса терапии в целом подтвердила улучшение у пациентов всех групп, но межгрупповое сравнение выявило значимо лучшие результаты у больных I группы. Отсутствие же после лечения статистически подтверждённых отличий по примененым критериям диагностики между II и IIІ группами свидетельствует о недостаточно высокой эффективности лечения с использованием «стандартных» аурикуляных зон.

При сравнительной оценке эффективности лечебных методикпо отдаленным результатам, выявлены дополнительные отличительные особенности применяемых лечебных подходов.

Во всех группах как непосредственно после лечения, так и спустя шесть месяцев, отмечалась положительная динамика восстановления, отражающаяся в данных оценки клинического состояния больных и результатах дополнительных методов обследования. Тем не менее, в I группе больных достигнута более выраженная эффективность лечения, чем во II и III группах (P<0,005); состояние же пациентов II группы было значимо лучше, чем в III группе $(\mathrm{P}<0,05)$.

Эти межгрупповые

отличия подтверждаются результатами неврологического исследования, иммунными данными и тестовым контролем психического состояния больных. При этом результаты лечения III группы согласуются с результатами исследований, представленных в литературе [10].

Уменьшение частоты и выраженности головной боли, усталости, восстановление полноценного сна и жизненной активности, а также нормализации объективных данных позволяет рассматривать проводимую дифференцированную аурикулотерапию в комплексе с медикаментами не в качестве локального, а системного метода, действующего на уровне различных функциональных систем организма. Об этом свидетельствует и положительная динамика иммунных изменений, и тестовая оценка психического состояния пациентов.

Более эффективные отдаленные результаты лечения у пациентов I группы в отличие от II и III группы объяснимы более низкой эффективностью медикаментозных препаратов в Ш группе и нецеленаправленностью аурикулопунктуры (во II группе).

Таким образом, выявленное через шесть месяцев после лечения отличие между показателями трёх групп, не только подтверждает превосходство комплексной терапии, но и демонстрирует преимущества дифференцированной аурикулотерапии по сравнению со «стандартной» и только медикаментозной.

Вместе с тем, непосредственно после проведенного лечения пациенты I группы, страдающие ХЕГБ от 5 до 10 лет, показали значимо лучшие $(\mathrm{P}<0,005)$ результаты уменьшения головной боли, при сравнении с больными с такой же длительностью заболевания двух других групп. Иных различий между группами не обнаружено $(\mathrm{P}>0,05)$.

Через шесть месяцев после лечения, при сопоставлении состояния больных I и II групп, выявлены статистически достоверные отличия между группами. У больных I группы с длительностью заболевания до 5 лет, от 5 до 10 лет и от 10 до 15 лет выявлены лучшие $(\mathrm{P}<0,005)$ показатели эффективности лечения, по отношению к пациентам с такой же длительностью заболевания во II группе. Статистический анализ результатов оценки состояния больных этих групп с иной длительностью заболевания не подтвердил межгрупповые различия.

Установлено отличие между больными I и II групп, с длительностью заболевания до 5 $(\mathrm{P}<0,005)$, до $10(\mathrm{P}<0,005)$ и до 15 лет $(\mathrm{P}<0,05)$. В этих группах больные с давностью ХЕГБ до 3 лет имели одинаковую выраженность восстановительных процессов (P>0,1). Между больными II и III групп выявлена разница 
$(\mathrm{P}<0,05)$ по всем возрастным подгруппам.

Целостная оценка этих результатов, полученных непосредственно после лечения и через шесть месяцев, показывает гораздо лучшие восстановительные способности у пациентов с давностью заболевания до 3 (Р $<0,005)$.

Вероятно, такая зависимость восстановления связана с компенсаторными возможностями организма. При этом эффективность восстановления соответствует методу лечения.

Проведенное исследование позволяет оценить комплексное медикаментозноаурикулярное лечение с применением дифференцирован-ного акупунктурных зон как обладающее значимыми преимуществами перед аналогичным, методом, в котором в качестве аурикулярных зон используются точки «общего действия», а также перед медикаментозным лечением.

Выводы:

1. Обнаружено, что локализация головной боли при ХЕГБ зависит от патологии определенных внутренних органов.

2. Выявлена эффективность использования методов аурикулодиагностики и пульсовой диагностки в качестве экспрессдиагностического метода выявления патологии внутренних органов у пациентов с ХЕГБ.

3. Дифференцированная аурикулотерапия в комплексе с медикаментозным лечении больных с ХЕГБ, существенно повышало ее эффективность и приводило к более выраженной регрессии болевого синдрома по сравнению с результатами стандартной аурикулотерапии или только медикаментозного лечения.

\section{ЛИТЕРАТУРА}

1. Mathew N.T., Kurman R., Perez F. Drug induced refractory headache -clinical features and management. Headache 1986; 26:317; Gay L. Lipchik, PhD and Justin M. Nash Management of chronic tensiontype headache. Neurology 2002; 59:8-13

2. Р. Ф. Тахмазов Теоретические и практические основы современной Восточной медицины. Баку 2000

3. Самосюк И.3., Лысенюк В.П. Акупунктура. Энциклопедия. Киев, Москва, Украинская энциклопедия, 1994., с.206-208

4. Stewart W.F., Lipton R.B. The economic and social impact of migraine. Eur Neurol 1994:34(suppl 2): $\mathrm{S} 12-7$

5. M Karst, M Reinhard, P Thum, B Wiese, J Rollnik, $M$ Fink Needle acupuncture in tension-type headache: a randomized, placebo-controlled study. Cephalalgia Volume 21, Issue 6, pages 637-642, July 2001

6. Иваничев Г. А. Клинические лекции по нейрофизиологии акупунктуры. Казань, 1994. - 48c.; Амелин А.В., Зайцев А.А., Иванов В.Е.,
Игнатов Ю.Д., Коренко Л.А., Скоромец А.А. Изучение механизмов действия амитриптилина и акупунктуры с помощью ноцицептивного сгибательного рефлекса у пациентов с хронической головной болью // Анестезиология и реаниматология, 1998, № 5, С.19-21.

7. Peter J. Goadsby, M.D., D.Sc., Richard B. Lipton, M.D., and Michel D. Ferrari, M.D., Ph.D. Migraine - Current Understanding and Treatment, N Engl J Med 2002; 346:257-270 January 24, 2002

8. Silberstein SD, Lipton RB, Solomon S, et al. Classification of daily and near-daily headaches: proposed revisions to the IHS criteria. Headache 1994; 34: $1-7$.

9. Табеева Д.М. Руководство по иглорефлексотерапии. М., 1980

10. Ширалиева Р.К., Тахмазов Р.Р. Применение акупунктуры в терапии головной боли, Azərbaycan Tibb jurnal1, 2006, №1 c 135-137. 
XÜLASə

\title{
XRONIKİ HəR GÜN TOKRARLANAN BAŞ AĞRILARININ KOMPLEKS MÜALICOSINDӘ AURIKULOTERAPIYA
}

\author{
Təhməzov R.R. \\ Ә. Oliyev adına Azarbaycan Dövlat Həkimlari Təkmilləşdirmə Institutu, Bakı
}

Təqdim edilmiş işdə ilk dəfə göstərilib ki aurikuloterapiyanın dərman müalicəsi ilə kompleks şəkildə tətbiqi onların ayrı-ayrılıqda istifadəsindən daha üstündür. Bundan başqa hazırkı işdə aurikular zonaların diferensial seçimi “ümumu təsirli” bioloji aktiv nöqtələri olan aurikular zonaların seçimindən və dərman müalicəsindən daha üstün olmuşdur.

Açar sözlər: aurikuloterapiya, qeyrimedikamentoz terapiya, akupunktura.

\section{SUMMARY \\ AURIKULOTERAPY IN COMPLEX
TREATMENT OF CHRONIC DAILY HEADACHE}

Tahmazov R.R.

Azerbaijan State Advanced Training Institute for Doctors named after A.Aliyev, Baku

The present work for the first time demonstrated significant benefit of integrated application of auriculotherapy together with drug treatment in comparison with separate use of these methods. Moreover this work showed advantage of differential selection of auricular zones in comparison with choice of these zones of biological active points with "common effect" and also in comparison with drug therapy.

Key words: auriculotherapy, non-drug therapy, acupuncture.

Redaksiyaya göndərilmişdir: 02.12.2011

Təkrar işləməyə qaytarılmışdır: 31.12.2011

Çapa tövsiyyə edilmişdir: 31.01 .2012

Rəyçi: Z.Sadıxova, t.ü.f.d., dosent 